\title{
ANALISIS KEGAGALAN PISTON PADA KENDARAAN RODA EMPAT KAPASITAS 1000 CC
}

\author{
Ahmad Zayadi \\ Program Studi Teknik Mesin, Fakultas Teknik Dan Sains Universitas Nasional \\ email : zayadiahmad43@gmail.com
}

\begin{abstract}
Pistons are one of the main components of a 1000 cc engine that functions as a pressure suppressor and a recipient of pressure combustion in the combustion chamber. In the examination of the $1000 \mathrm{cc}$ sedan engine that has been operating for 30,000 hours found a rough sound on the engine and experienced loss compression on the cylinder block number 2. The purpose of the study was to obtain the factors causing the deformation of the piston $1000 \mathrm{cc}$ sedan vehicles. The research method used is metallographic observation using ASTM E 3 and ASTM E 112, testing hardness using ASTM E 92 and SNI 19-0409-1989 and testing chemical composition using ASTM A 751. The results of research on piston damage can be seen that observation macrostructure proves that there is plastic deformation on the surface area of the piston material, the results of microstructure observation are known to occur microcrack on the top surface of the right side of the piston, there is no change in micro hardness between the piston material in the deformed area with the deformed piston material hardness, piston material made of alloy Al-Si. In the area of the piston surface that experiences deformation, $\mathrm{Mg} 2 \mathrm{Si}$ and Mg2Al3 compounds are formed, these compounds which cause microcrack on the piston's upper surface. Plastic deformation on the piston surface occurs due to a collision between the piston surface and the cylinder head due to the buildup of crust on the piston surface.
\end{abstract}

Keywords: piston, deformation, metallography, hardness, chemical composition

\section{PENDAHULUAN}

Kendaraan roda empat dengan kapasitas silinder mesin 1000 cc merupakan jenis kendaraan yang banyak diminati oleh masyarakat Indonesia, terutama yang tinggal di kota-kota besar, seperti Jakarta dengan tingkat kemacetan lalu lintas yang tinggi. Hal ini disebabkan mobil tersebut ramah lingkungan, hemat bahan bakar, dan memiliki desain yang compact dan ringan. Mesin dengan kapasitas silinder mesin $1000 \mathrm{cc}$ memiliki 3 (tiga) silinder yang menggunakan sudut putar sebesar $120 \mathrm{O}$ sehingga putarannya seimbang. Meskipun mesin 3 silinder putarannya dapat mengimbangi satu sama lain, pembakarannya tetap menimbulkan getaran. Hal ini dikarenakan tidak ada silinder lawan yang mengimbangi, seperti pada mesin 4 silinder. Piston merupakan salah satu komponen penting dalam mesin $1000 \mathrm{cc}$ dengan 3 silinder adalah piston. Piston berfungsi sebagai penekan udara masuk dan penerima tekanan hasil pembakaran pada ruang bakar. Piston terhubung ke poros engkol (crankshaft) melalui batang piston (connecting rod) yang akan menghasilkan kinerja 4 langkah dalam pembakaran pada mesin 4 tak, yaitu langkah hisap, langkah kompresi, langkah usaha, dan langkah buang. Pada umumnya mesin mobil perlu dilakukan perawatan secara rutin setiap kelipatan $\quad 10.000$ jam untuk menjaga kinerja mesin tetap bekerja secara normal. Selain itu perawatan rutin juga berguna untuk mengantisipasi apabila terjadi gangguan pada komponen-komponen mesin yang dapat mengganggu kinerja mesin.

Dalam proses perawatan yang dilakukan ditemukan adanya gejala kerusakan pada piston yang ditandai dengan adanya bunyi kasar pada mesin yang disebabkan kinerja piston tidak maksimal. Pada saat proses pemeriksaan terdengar bunyi kasar pada mesin ditemukan adanya loss compression pada silinder nomor 2 . Hasil pengukuran tekanan kompresi pada silinder no. 2 berada di bawah batas normal yaitu sebesar 6 Psi sedangkan batas normal tekanan kompresi adalah 11,5 Psi. Pada silinder no. 1 dan no. 3, tekanan kompresinya adalah 11,5 Psi sehingga silinder no. 1 dan 3 tidak terjadi loss compresion. 
Dari hasil pemeriksaan pada silinder nomor 2, loss compression diduga akibat adanya permukaan piston yang mengalami deformasi. Piston yang mengalami deformasi baru beroperasi selama 30.000 jam sedangkan operasi normal dari piston yaitu 200.000 jam. Piston tersebut tidak dapat digunakan lagi dan harus dilakukan penggantian dengan piston yang baru. Tujuan penelitian adalah untuk mendapatkan faktor penyebab terjadinya kegagalan piston kendaraan roda empat kapasitas $1000 \mathrm{cc}$ yang terjadi selama 30.000 jam. Faktor penyebab kegagalan tersebut dapat diketahui dengan cara melakukan pengujian yang meliputi: Pengamatan metalografi untuk mengetahui makrosutruktur dan mikrostruktur pada material piston yang mengalami kegagalan. Pengujian kekerasan untuk mengetahui kekerasan material piston yang mengalami kegagalan. Pengujian komposisi kimia untuk mengetahui komposisi kimia dari material piston yang mengalami kegagalan.

\section{METODOLOGI PENELITIAN}

Diagram alir proses pelaksanaan penelitian dapat dilihat pada gambar dibawah ini:

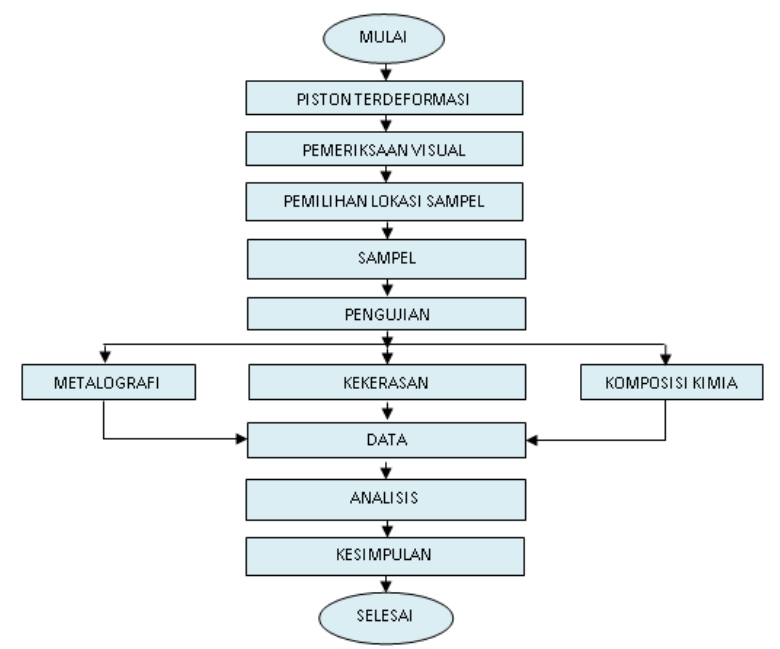

Gambar 1. Diagram Alir Analisis Kegagalan Dari Piston Untuk Kendaraan Roda Empat Kapasitas $1000 \mathrm{Cc}$

\section{ANALISIS DAN PEMBAHASAN DATA}

Penelitian yang dilakukan terhadap kegagalan piston pada kendaraan roda empat kapasitas 1000 cc dilakukan melalui beberapa tahap, yaitu pengukuran dimensi benda uji, pemeriksaan visual, makrostruktur, mikrostruktur, pengujian kekerasan dan pengujian komposisi kimia. Kegiatan pengujian tersebut dilakukan di B2TKS BPPT Kawasan PUSPIPTEK, Tangerang Selatan.

\section{MAKROSTRUKTUR}

Pengujian makrostruktur dilakukan pada daerah yang mengalami kerusakan untuk melihat permukaan piston roda empat kapasitas 1000 CC. Pemeriksaan dilakukan dengan mikroskop stereo perbesaran 12x dan 25x seperti Gambar 2.

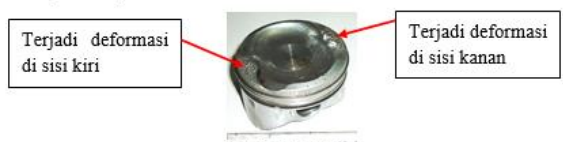

Gambar 2. Piston Sedan 1000 Cc Yang Mengalami Deformasi

Gambar diatas memperlihatkan adanya deformasi di permukaan sisi kiri dan sisi kanan bagian atas piston. Deformasi pada permukaan atas piston tersebut diduga akibat benturan dengan kepala silinder yang disebabkan karena adanya penumpukan kerak pada bagian atas piston.
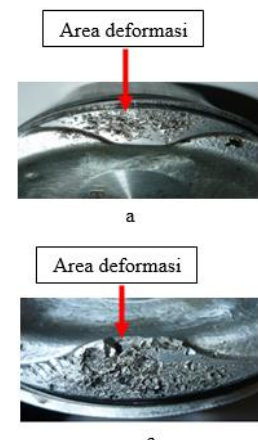
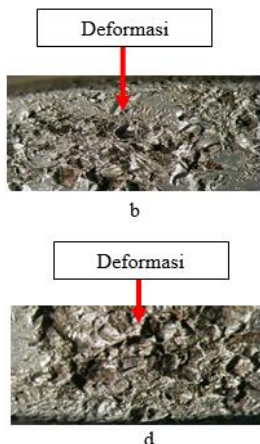

Gambar 3. Makrostruktur Permukaan Bagian Atas Piston Mengalami Deformasi

Keterangan gambar:

a. Area bagian permukaan piston sisi kiri yang mengalami deformasi.

b. Area bagian permukaan piston sisi kiri yang mengalami deformasi. (Perbesaran : 25x)

c. Area bagian permukaan piston sisi kanan yang mengalami deformasi.

d. Area bagian permukaan piston sisi kanan yang mengalami deformasi. (Perbesaran : 25x)

Kerusakan yang terjadi di bagian atas (sisi ruang bakar) berupa cacat akibat benturan piston dengan silinder head yang menyebabkan terjadinya deformasi pada material piston. Selain itu, pada permukaan piston terlihat adanya kerak hitam yang cukup tebal yang menempel pada permukaan piston. Kerusakan tersebut dapat menimbulkan cacat pada piston yang diduga akan mengakibatkan suara mesin menjadi kasar dan loss compression. 


\section{MIKROSTRUKTUR}

Pengujian mikrostruktur dilakukan terhadap piston yang mengalami kerusakan, hasilnya dapat dilihat pada gambar 4 .
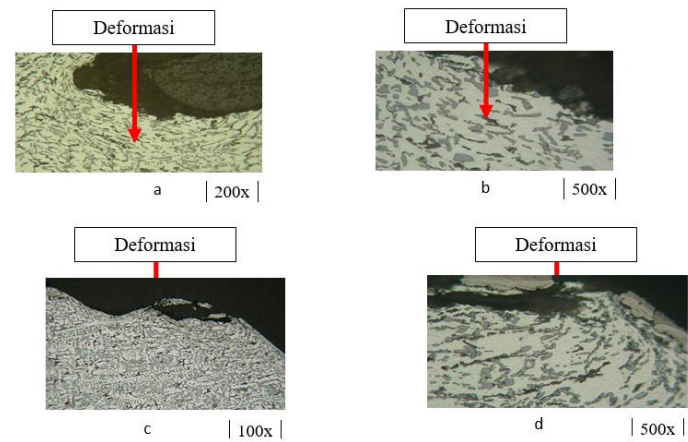

Gambar 4. Mikrostruktur Permukaan Atas Piston Sedan 1000 CC

Keterangan Gambar 4 :

a. a dan b hasil pengujian mikrostruktur sisi kiri permukaan atas material piston

b. c dan d hasil pengujian mikrostruktur sisi kanan permukaan atas material piston

Gambar 4. Memperlihatkan potongan sampel piston memanjang yang mengalami cacat akibat beban benturan yang cukup besar. Hal tersebut didukung dengan adanya deformasi struktur. Pada area deformasi sisi kanan permukaan piston terjadi benturan yang paling keras dan diduga akan menimbulkan crack pada area tersebut. Sedangkan pada area deformasi diarea sisi kiri permukaan piston hanya terjadi deformasi kecil yang tidak menimbulkan crack. Terjadinya retakan kecil atau microcrack pada area deformasi sisi kanan permukanan piston dapat dilihat pada Gambar 5.
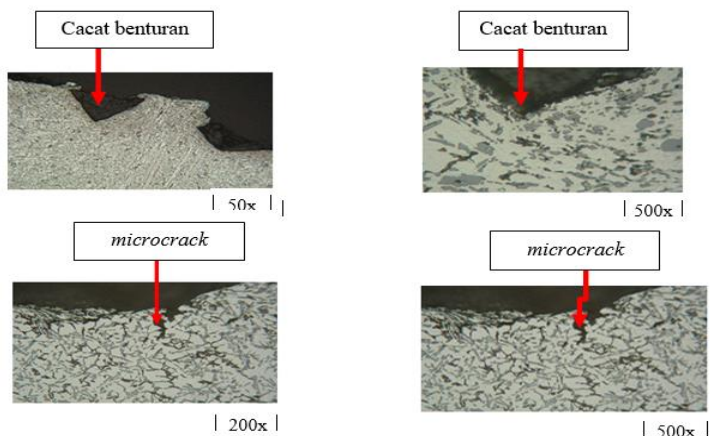

Gambar 5. Cacat Pada Piston (Etsa : Perbesaran 50x, 100x, 200x, dan 500x)

Gambar 5 memberikan informasi bahwa terdapat cacat tajam yang membentuk sudut yang diindikasikan membentur benda yang cukup tajam. Pada area benturan ditemukan retakan halus atau microcrack. Retakan halus tersebut membentuk suatu rongga atau cekungan yang berdampak pada kinerja piston menjadi menurun sehingga menimbulkan efek pada mesin berupa gejala loss compression dan noise. Pengujian mikrostruktur juga dilakuakn di area terdekat sekitar area yang terjadi deformasi pada material piston. Hasil pengujian dapat dilihat pada Gambar 6.
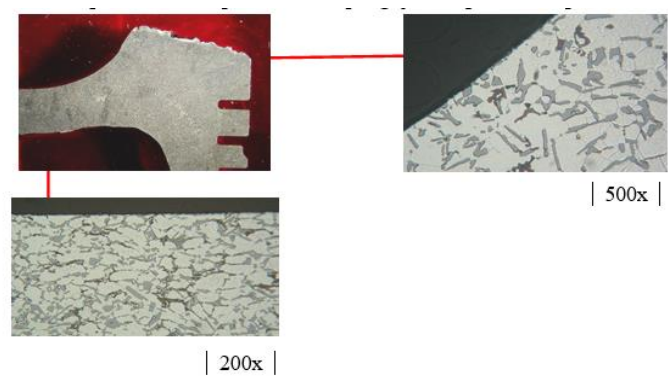

Gambar 6 Area Terdekat dengan Area Deformasi (etsa : dix's keller reagent)

Gambar 6. Memberikan informasi bahwa area permukaan cekung (bagian tengah piston) pada piston sisi atas yang terdekat dengan area piston yang mengalami deformasi tidak ditemukan adanya cacat. Hal ini menunjukkan bahwa di area tersebut tidak terjadi benturan antara kepala silinder dengan piston yang disebakan oleh penumpukan kerak. Dari penjelasan hasil pengujian mikrostruktur dapat dihasilkan 3 kesimpulan, yaitu :

1. Area sisi kiri permukaan atas piston terjadi deformasi tetapi tidak menimbulkan keretakan / crack.

2. Area sisi cekung (tengah) permukaan atas piston tidak terjadi deformasi dikarenakan tidak terjadi benturan antara piston dengan kepala silinder yang disebabkan oleh kerak.

3. Area sisi kanan permukaan atas piston terjadi deformasi yang sangat besar sehingga menimbulkan retak halus/microcrack, hal ini terjadi dikarenakan penumpukan kerak terbanyak berada di area sisi kanan permukaan piston. Penumpukan kerak yang cukup banyak diarea sisi kanan permukaan piston disebabkan karena area tersebut dekat dengan katup buang sehingga kerak cenderung tertumpuk diarea tersebut.

\section{KEKERASAN}

Gambar 6. Memberikan informasi bahwa area permukaan cekung (bagian tengah piston) pada piston sisi atas yang terdekat dengan area piston yang mengalami deformasi tidak ditemukan 
adanya cacat. Hal ini menunjukkan bahwa di area tersebut tidak terjadi benturan antara kepala silinder dengan piston yang disebakan oleh penumpukan kerak. Dari penjelasan hasil pengujian mikrostruktur dapat dihasilkan 3 kesimpulan, yaitu :

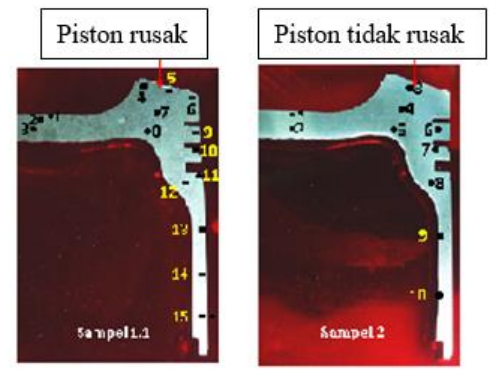

Gambar 7. Titik Lokasi Uji Kekerasan Material Piston

Gambar 7. Memperlihatkan titik lokasi sampel yang diuji kekerasannya. Sampel 1 (Piston yang mengalami kerusakan) terdapat 15 titik lokasi uji kekerasan dan sampel 2 (Piston yang tidak mengalami kerusakan) terdapat 10 titik lokasi uji kekerasan.

Tabel 1. Nilai Uji Kekerasan Material Piston

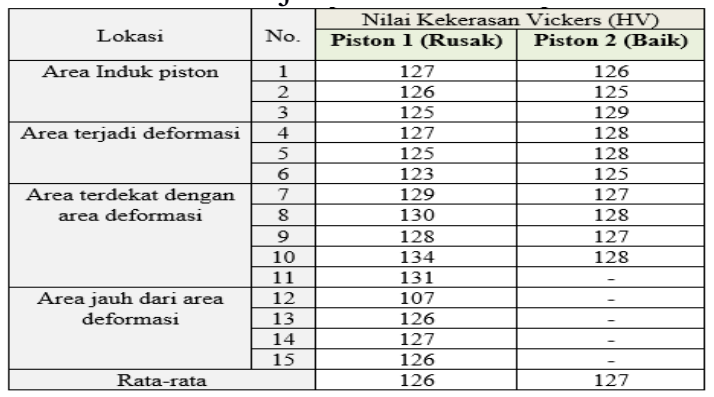

Tabel 1. Menunjukkan bahwa kekerasan ratarata material piston yang mengalami deformasi adalah $126 \mathrm{HV}$ dan kekerasan rata-rata material piston yang tidak terdeformasi adalah $127 \mathrm{HV}$. Dari sisi kekerasan ternyata tidak ditemukan adanya perbedaan kekerasan material di sekitar yang mengalami cacat dengan material dasar piston. Hal ini menunjukkan bahwa deformasi yang terjadi pada permukaan piston tidak berdampak pada perubahan kekerasan material dari piston itu sendiri. Deformasi yang terjadi pada permukaan atas piston menyebabkan terjadinya microcarck sesuai dengan hasil pengujian mikrostruktur. Adanya microcrack pada permukaan atas piston dapat menimbulkan suara kasar pada mesin yang bersumber dari tekanan fluida berupa udara di dalam ruang bakar menurun (Kegagalan pada area adiabatik) yang menyebabkan langkah kompresi menjadi tidak stabil. Dampak dari ketidakstabilan langkah kompresi yaitu terjadinya loss compression yang akan mengakibatkan pembakaran tidak sempurna sehingga menimbulkan tumpukan kerak jelaga sisa pembakaran di dalam ruang bakar dan tertumpuk diatas permukaan piston. Dengan demikian penanganan yang dilakukan untuk perbaikan prolem tersebut yaitu dilakukan penggantian piston baru.

\section{KOMPOSISI KIMIA}

Pengujian komposisi kimia material piston dilakukan dengan menggunakan spectrometer untuk mengetahui kandungan unsur penyusun material piston. Data uji komposisi kimia material piston ditunjukkan pada Tabel 4.2. Kandungan unsur pemadu utama material piston adalah $81,10 \% \mathrm{Al}$ dan $14,851 \%$ Si dengan unsur pemadu lain adalah $0,533 \% \quad \mathrm{Fe}$ dan $0,938 \% \mathrm{Mg}$. Berdasarkan komposisi unsur pemadu tersebut diketahui bahwa material piston terbuat dari paduan Al-Si.

Tabel 2. Data Komposisi Kimia Piston Yang Mengalami Cacat

\begin{tabular}{|c|c|c|c|}
\hline \multirow{2}{*}{ No } & \multirow{2}{*}{ Unsur } & $\begin{array}{c}\text { Piston yang } \\
\text { terdeformasi }\end{array}$ & Piston yang tidak terdeformasi \\
\cline { 3 - 4 } & & $\begin{array}{c}\text { Nilai Kandungan } \\
\text { Unsur (\% berat) }\end{array}$ & Nilai Kandungan Unsur (\% berat) \\
\hline 1 & $\mathrm{Al}$ & 81.10 & 81.15 \\
\hline 2 & $\mathrm{Fe}$ & 0.533 & 0.542 \\
\hline 3 & $\mathrm{Si}$ & $\mathbf{1 4 . 8 5 1}$ & $\mathbf{1 4 . 9 4 3}$ \\
\hline 4 & $\mathrm{Mn}$ & 0.051 & 0.052 \\
\hline 5 & $\mathrm{Mg}$ & 0.938 & 0,944 \\
\hline 6 & $\mathrm{Cr}$ & 0.012 & 0,013 \\
\hline 7 & $\mathrm{Ni}$ & 1.034 & 1.032 \\
\hline 8 & $\mathrm{Cu}$ & 1.138 & 1.137 \\
\hline 9 & $\mathrm{~V}$ & 0.011 & 0.012 \\
\hline 10 & $\mathrm{Ti}$ & 0.024 & 0.025 \\
\hline 11 & $\mathrm{Sn}$ & 0.544 & 0.554 \\
\hline 12 & $\mathrm{~Pb}$ & 0.001 & 0.001 \\
\hline 13 & $\mathrm{Co}$ & 0.007 & 0.008 \\
\hline 14 & $\mathrm{Zn}$ & 0.000 & 0.000 \\
\hline
\end{tabular}

Dari Tabel 2 diketahui bahwa untuk piston yang terdeformasi terjadi penurunan kandungan unsur Al sebesar 0,05\%, kandungan unsur $\mathrm{Fe}$ sebesar 0,009\%, kandungan unsur $\mathrm{Si}$ sebesar $0,092 \%$ dan kandungan unsur $\mathrm{Mg}$ sebesar $0,006 \%$. Hal ini menunjukkan bahwa deformasi yang terjadi pada material piston mempengaruhi terjasdinya interaksi antara unsur-unsur pemadu dalam material piston sehingga akan terbentuk senyawa $\mathrm{Mg} 2 \mathrm{Si}$ dan Mg2Al3. Pembentukan senyawa tersebut menyebabkan terjadinya beda tegangan dalam komponen material piston yang mengakibatkan terjadinya tegangan sisa. Tegangan sisa yang ditimbulkan menyebabkan area material piston mengalami keretakan halus atau microcrack. Dalam jangka waktu yang lama keretakan tersebut akan menimbulkan korosi dan terjadinya penumpukan kerak yang berlebih serta rongga keretakan yang semakin besar yang berakibat akan menimbulkan kinerja piston 
menurun dan mesin tidak bisa bekerjas secara normal.

\section{Analisis Kerusakan Piston Kendaraan Roda Empat Kapasitas 1000 CC}

Dari penjabaran hasil analisis pengujian material piston yaitu pengamatan metalografi, pengujian kekerasan dan pengujian komposisi kimia dapat diketahui bahwa kerusakan piston disebabkan oleh adanya penumpukan kerak pada permukaan piston, sehingga celah antara permukaan piston dengan kepala silinder menjadi kecil pada saat piston beroperasi. Adanya kerak tersebut dapat menimbulkan benturan antara permukaan piston dengan kepala silinder. Benturan tersebut terjadi berulang sehingga dapat menyebabkan terjadinya deformasi plastis pada permukaan piston. Seiring dengan berjalannya waktu operasi piston, benturan tersebut dapat menimbulkan keretakan halus pada area piston yang terdeformasi. Keretakan halus tersebut diduga sebagai penyebab terjadinya loss compression dan bunyi kasar pada mesin.

\section{SIMPULAN}

Berdasarkan hasil pengkajian data penelitian terhadap kerusakan piston pada kendaraan roda empat 1000 cc maka dapat disimpulkan sebagai berikut.

1. Pengamatan makrostruktur membuktikan bahwa terjadi deformasi pada area permukaan atas material piston.

2. Pengamatan mikrostruktur menunjukan bahwa area deformasi sisi kiri permukaan atas piston tidak terjadi keretakan, area cekung atau area tengah permukaan piston tidak mengalami cacat/deformasi dan di area sisi kanan terjadi deformasi yang sangat besar sehingga minimbulkan keretakan halus (microcrack) di area tersebut.

3. Tidak ada perbedaan nilai kekerasan mikro antara material piston pada daerah yang terdeformasi dengan kekerasan material piston yang tidak terdeformasi.

4. Piston sedan $1000 \mathrm{cc}$ terbuat dari paduan AL-Si. Pada area permukaan piston yang mengalami deformasi terbentuk senyawa $\mathrm{Mg} 2 \mathrm{Si}$ dan Mg2A13. Senyawa tersebut yang menyebabkan terjadinya keretakan halus (microcrack) pada permukaan atas piston.
5. Kerusakan dini pada material piston sedan 1000 cc disebabkan oleh adanya microcrack pada material bagian permukaan sisi atas piston akibat adanya benturan permukaan piston dengan kepala silinder.

\section{DAFTAR PUSTAKA}

Nurhadi. 2010. Studi karakteristik material piston dan pengembangan prototipe piston berbasis limbah piston bekas. Tesisis. Program studi magister teknik mesin program pasca sarjana universitas diponegoro semarang.

Wahyu, B, U. 2008. Pengaruh penambahan modifier stronsium dan phosphor serta proses perlakuan panas pada sifat mekanik dan struktur mikro alumunium AC8H untuk produk piston. Tesis. Fakultas teknik program studi metalurgi dan material universitas Indonesia. Depok.

Hasiolan, P. 2003. Analisis Kualitas Material Piston Pada Sepeda Motor Produk China Dan Produk Jepang. Skripsi. Teknik Mesin. Universtitas Nasional.

ASTM Standards, 2003, Metal Test Methods and Analytical Procedures, volume 03.01, West Conshohocken United States.

Duskiardi, T, S., 2002, Pengaruh Tekanan dan Temperatur Die Proses Squeeze Casting terhadap Kekerasan dan Struktur Mikro pada Material Piston Komersial Lokal, Jurnal Teknik Mesin Vol. 4 No. 1 April 2002, Universitas Kristen Petra Surabaya, pp. 1-5.

ASTM. Metals Test Methods And Analytical Procedures, 2002, Vol. 03.01. West Chonshohocken. ASTM International.

ASM International, 1993, ASM Specialty Handbook: Alumunium and Alumunium Alloys, Ohio.

Surdia, Tata \& Saito, Shinroku. 1992. Pengetahuan Bahan Teknik (edisi kedua). Jakarta: Pradnya Paramita.

American Society Of Material, 1990, Handbook Vol 13, Corrosion.

Anonim, Buku Pedoman Perbaikan dan Informasi Teknik Mesin $1000 \mathrm{cc}$ PT ASTRA DAIHATSU MOTOR TECHNICAL SERVICE DIVISION,

Anonim, BASIC 1 PSG DAY RELEASE, Astra International Training Center.

Anonim, Buku Ajar Mesin Konversi Energi PTM307.

Doehler, H., Die Casting, McGraw Hill Book Company, New York. 